\title{
Characterization of the repetitive sequences in a 200-kb region around the rice waxy locus: diversity of transposable elements and presence of veiled repetitive sequences
}

\author{
Hironori Nagano, Motoyuki Kunii, Takayuki Azuma, \\ Yuji Kishima* and Yoshio Sano \\ Laboratory of Plant Breeding, Faculty of Agriculture, Hokkaido \\ University, Sapporo 060-8589, Japan
}

(Received 16 January 2002, accepted 23 March 2002)

\begin{abstract}
Repetitive genomic sequences might have various structural features and properties distinct from those of the known transposable elements (TE). Here, the content and properties of the repetitive sequences present in a 200-kb region around the rice waxy locus were analyzed using the available rice genomic database. In our previous Southern blotting analysis, $70 \%$ of the segments in this region showed smeared patterns, but according to the present database analysis, the proportion of repetitive sequences in this region was only $15 \%$. The repetitive segments in this $200-\mathrm{kb}$ region comprised 75 repetitive sequences that we classified into 46 subfamilies: 21 subfamilies were known TEs or repetitive sequences and 25 subfamilies consisted of newly identified TEs or novel types of repetitive sequences. The region contains no long terminal repeat (LTR) retrotransposable elements, but miniature inverted repeat transposable elements (MITEs) constituted a major class among the elements identified. These MITEs showed remarkable structural divergence: 12 elements were found to be new members of known MITE superfamilies, while five elements had novel terminal structures, and did not belong to any known TE families. Interestingly, about $10 \%$ of the repetitive sequences, including virus-like sequences did not have any of the usual characteristics of TEs, suggesting that a certain proportion of repetitive sequences that might not share the transpositional mechanisms of known elements are dispersed in the compact rice genome.
\end{abstract}

\section{INTRODUCTION}

Interspersed repetitive DNA is an intrinsic component of the fundamental frame of the genome architecture of eukaryotes (Britten and Kohne, 1968). In many cases, repetitive sequences (RSs) are referred to as transposable elements (TEs), which are usually categorized into two classes: class I, retroelements, which transpose replicatively by means of an RNA intermediate, and class II, nonreplicative elements, of which the DNA transposes in the cut-and-paste fashion (Charlesworth et al., 1995; McDonald, 1993). Although such representative TEs have been intensively mined from the genome databases based on sequence homology, and studied major players in the expression repetitiveness (Bureau et al., 1996; Jurka, 1998), few attempts have been made to isolate the

Edited by Eiich Ohtsubo

* Corresponding author. E-mail: kishima@abs.agr.hokudai.ac.jp entire range of RSs distributed in a genome or a portion of a genome.

The genomes of various grass-species have been dissected to elucidate the genome organization and function with respect to the $\mathrm{C}$ value paradox proposed by Thomas (1971), i. e., the number of genes in different species is basically similar, while the genome sizes vary greatly. The rice genome is the smallest in size (about $430 \mathrm{Mb}$ ) among the genomes of grass species that have been characterized (Arumuganathan and Earle, 1991). Compared with maize and barley, which possess larger genomes, rice has a lower frequency of long terminal repeat retrotransposons (LTR elements) in its genome (Bennetzen, 2000). In the $340-\mathrm{kb} A d h 1-A d h 2$ region of the rice genome, seven LTR elements (corresponding to $14 \%$ of this region) were found (Tarchini et al., 2000), whereas in the homeologous region of maize, the proportion of the LTR elements was much higher (74\%) (SanMiguel et al., 1996). Similarly, the size difference 
between the homeologous sequences in rice chromosome 3 and barley chromosome $5 \mathrm{H}$ is explained by the proportion of LTR elements (Dubcovsky et al., 2001). The difference of the proportions of LTR elements between rice and these two crops accounts for the $\mathrm{C}$ value paradox in these grass species.

Despite the smaller number of LTR elements in the rice genome, Southern hybridization has shown that various rice genomic probes produce smeared patterns, which implies the presence of RSs. In fact, we previously reported that the use of probes from about $70 \%$ of the 260 $\mathrm{kb}$ surrounding the rice waxy ( $w x)$ locus resulted in smeared patterns in Southern blot analysis, which might have been due to repetitions of TEs or of novel repeated sequences (Nagano et al., 1999; Nagano et al., 2000). Two possible reasons for why the segments were recognized as smeared patterns in the blots were postulated: one is that long RSs are located in the segments used as probes, and the second is that the restriction fragments to be detected were masked by highly repetitive short sequences contained in the probe segments. It is necessary to divide the segments more finely to distinguish between these possibilities.

In this study, we explored the sequences that produce the smeared hybridization patterns observed when probing with the segments around the rice $w x$ locus. Detailed analysis of these repetitive sequences was made performed using the sequence information available in the rice genome database. We identified 75 $\mathrm{RSs}$ in the $200-\mathrm{kb}$ region around the $w x$ locus. Among these $75 \mathrm{RSs}$, there were no LTR elements, and most of the RSs were short (less than $1000 \mathrm{bp}$ ). Our survey of the region around $w x$ suggested that the rice genome contains numerous kinds of RSs that include not only a large
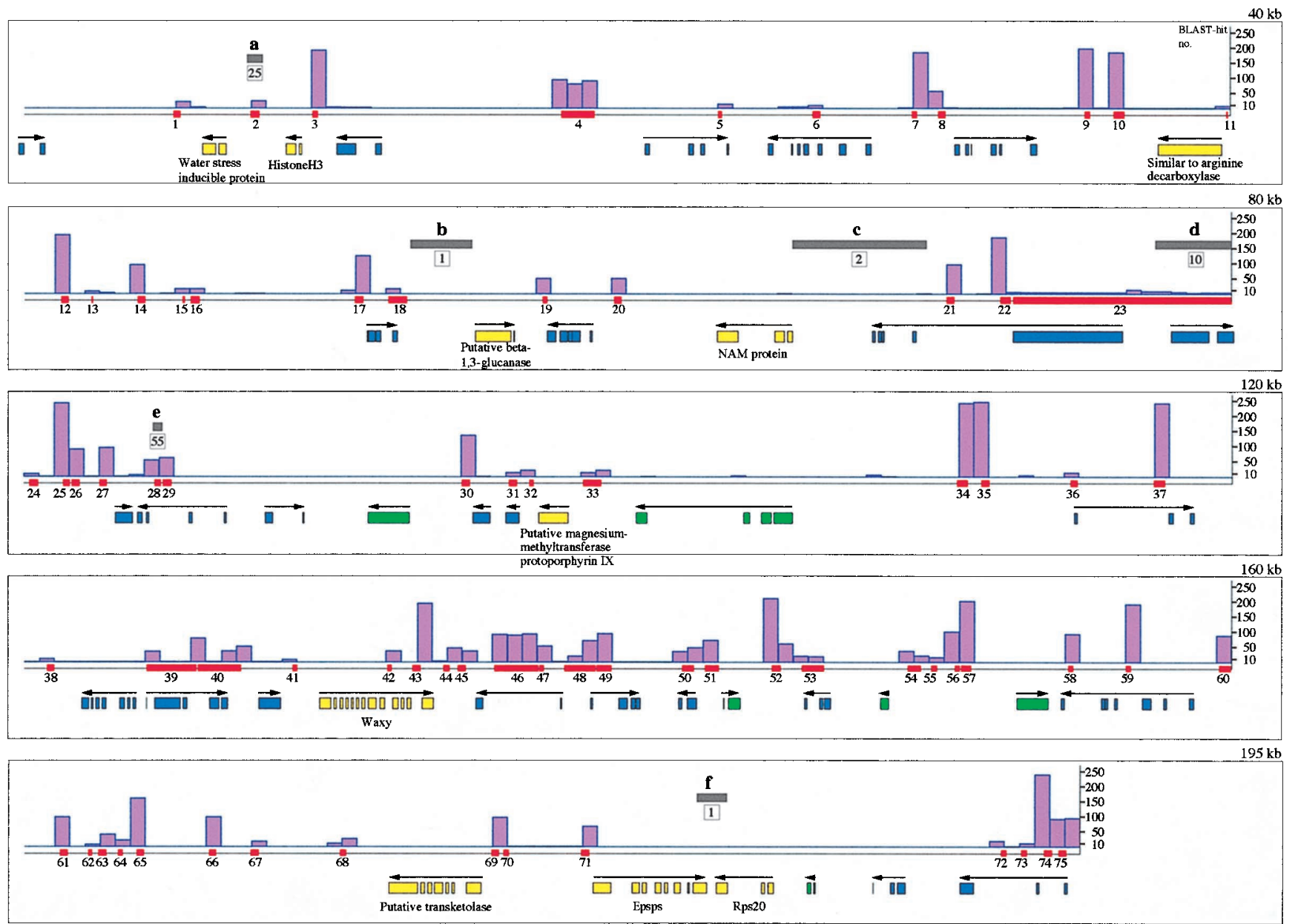

Fig. 1. Local genome map for repetitive sequences and genes in the 195-kb region around the $w x$ locus of rice chromosome 6 .

The purple histogram shows the blast-hit number every $500 \mathrm{bp}$. These are the number of homologous locations resulting from a blast search when a 500-bp segment was used as the query (version 2.0, http://www.ncbi.nlm.nih.gov/blast/) against the rice genome sequence. The red bars below the histogram indicate repetitive sequences identified by the database survey, and the numbers (RS no.) of the bars correspond to those of the element listed in Table 1. Arrows indicate the direction of transcription of a gene, and blue, green and yellow bars show open reading frames of hypothetical genes, unknown genes and known genes, respectively. The gray bars indicate the locations of hybridization probes used to determine the actual copy numbers as shown in Fig. 2. 
number of miniature inverted repeat transposable elements (MITEs) (Wessler et al., 1995), but also a certain proportion of hitherto unknown new elements without any features of ordinary TEs.

\section{MATERIALS AND METHODS}

RS site detection and mining TEs The sequence of the $195 \mathrm{~kb}$ around the $w x$ locus was obtained from two rice genomic clones (Accession nos. AP000559 and AP002542) located on the short arm of chromosome 6 . The $195-\mathrm{kb}$ sequence was divided into 390 segments of $500 \mathrm{bp}$ each, and each segment was subjected to blast search queries (version 2.0, http://www.ncbi.nlm.nih.gov/ blast/) against the rice genome sequences that had been registered in DDBJ (http://www.ddbj.nig.ac.jp/) as of November 2001, when the sequence of a quarter of the total length of the rice genome had been registered. The numbers of the rice genome sequences that shared similarity (blast score $>80$ ) with the query sequence were counted, and the number of locations homologous to each query segment was plotted. To establish a standard for RSs, Southern blotting analysis was performed using as probes several rice-genome segments with different repe- tition frequencies. The segments which were found to have over 10 repetitions were judged to be RS sites, because the Southern blotting of such segments resulted in smeared patterns (Fig. 2). To characterize RSs, we first looked for the end points of the RSs in multiple alignments of homologous sequences. Secondly, blast searches were performed to identify homologies with known TEs. We then attempted to find LTR or TIRs which might have flanked RSs in either the original query of the $w x$-proximal or the other homologous genomic regions. For RSs that did not have any characteristics of known TEs, the rice genome database was used to perform a search for related-empty site (RESite) (Le et al., 2000), which provides evidence for the transposition of RSs in the form of the empty donor site.

Southern hybridization Rice (var. Shimokita) genomic DNA was digested with HindIII, electrophoresed in $0.7 \%$ agarose gels, transferred to nylon membranes (Pall: Biodyne B), and hybridized. About $0.1 \mathrm{ug}$ of each of the indicated subcloned fragments or PCR fragments (Fig. 2) was prepared as an ECL probe. The membranes were washed twice after hybridization under the standard ECL conditions with $0.5 \mathrm{M} \mathrm{NaCl}$ at $42^{\circ} \mathrm{C}$ for $20 \mathrm{~min}$ and

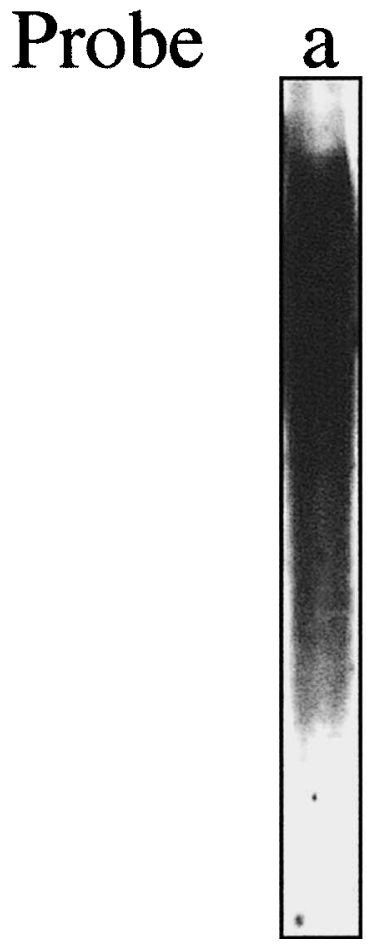

BLAST-hit no.
25

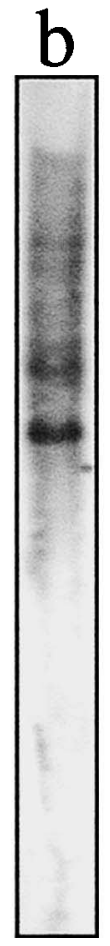

1

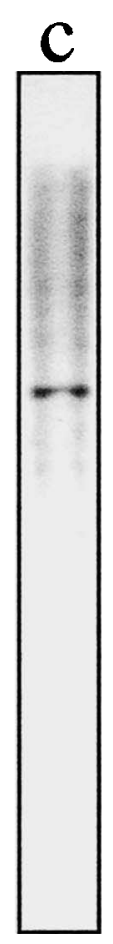

2

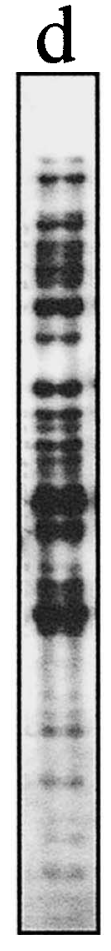

10

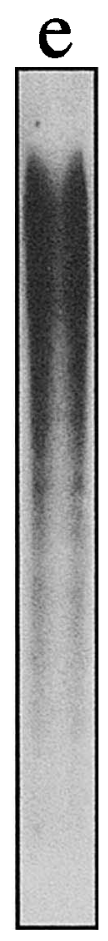

55

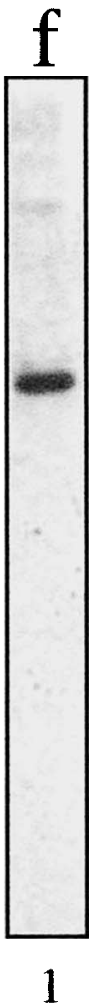

Fig. 2. Southern blot analysis to examine copy numbers at several locations with different reiteration frequencies.

Probes were prepared from six locations, as indicated in Fig. 1 (gray bars: a-f). The rice genomic DNA (var. Shimokita) was digested with HindIII and electrophoresed in $0.7 \%$ agarose gels. The reiteration frequencies of regions in the rice genome used as probes were determined by blast search and are indicated below the blots. 
Table 1. A list of repetitive sequences found in the 195-kb region around the $w x$ locus and the classification as to TEs.

\begin{tabular}{|c|c|c|c|c|}
\hline Class & Family & Subfamily & RS no. (Position) ${ }^{\mathrm{a}}$ & Reference \\
\hline I & p-SINE & p-SINE1 & 41(B: 90136-90259), 42(B: 93272-93396), 64(B: 124352-124461) & Umeda et al. (1991) \\
\hline \multirow[t]{32}{*}{ II } & CACTA-like & CACTA-like & 48(B: 99148-100167) & Tarchini et al. (2000) \\
\hline & \multirow[t]{12}{*}{ Tourist } & Castaway & 63(B: 123684-123948) & Bureau et al. (1996) \\
\hline & & Ditto/Type F & 16(A: 84793-85042), 27(A: 121759-122008) & Bureau et al. (1996) \\
\hline & & Gaijin & 56(B: 112132-112282) & Bureau et al. (1996) \\
\hline & & \multirow[t]{2}{*}{ Type $C$} & 12(A: 80473-80735), 34(B: 72197-72530), 37(B: 78729-79073) & \multirow[t]{2}{*}{ Tarchini et al. (2000) } \\
\hline & & & 52(B: 106052-106315), 57(B: 112314-112654), 74(B: 155068-155319) & \\
\hline & & Type $E$ & 59(B: 117784-117935) & Tarchini et al. (2000) \\
\hline & & Tabito $I$ & 1(A: 44224-44419), 2(A: 46779-47024), 68(A: 131694-131892) & This study \\
\hline & & Tabito II & 3(A: 48815-48961), 7(A: 68719-68871), 9(A: 74458-74609) & This study \\
\hline & & Tabito III & 5(A: 62279-62406) & This study \\
\hline & & Tabito IV & 10(A: 75414-75763) & This study \\
\hline & & Tabito $V$ & 30(A: 133780-134025) & This study \\
\hline & & Tabito VI & 58(B: 115872-116008) & This study \\
\hline & \multirow[t]{10}{*}{ Tnr1/Stowaway } & $\operatorname{Tnr} 1$ & 25(A: 120553-120778), 35(B: 73010-73256), 43(B: 94109-94346) & Umeda et al. (1991) \\
\hline & & Stowaway-Os4 & 44(B: 95126-95334) & Bureau et al. (1994a) \\
\hline & & Stowaway-Os6 & 70(B: 137134-137290) & Bureau et al. (1994a) \\
\hline & & Type A & 20(A: 98815-99051), 69(A: 136718-136965) & Tarchini et al. (2000) \\
\hline & & Type $B$ & 14(A: 83018-83258), 21(A: 109869-110107), 45(B: 95600-95843) & Tarchini et al. (2000) \\
\hline & & & 61(B: 122424-122661), 65(B: 124952-125186), 66(B: 127346-127569) & \\
\hline & & Kiseru $I$ & 17(A: 90206-90432) & This study \\
\hline & & Kiseru II & 29(A: 123860-124122) & This study \\
\hline & & Kiseru III & 38(B: 81992-82213) & This study \\
\hline & & Kiseru IV & 47(B: 98292-98457) & This study \\
\hline & \multirow[t]{4}{*}{ Mu-like } & Mermite & 54(B: 110574-110973) & Tarchini et al. (2000) \\
\hline & & Onaga I & 19(A: 96437-96575), 39(B: 85285-86938), 40(B: 86993-88410) & This study \\
\hline & & & 50(B: 103062-103426) & \\
\hline & & Onaga II & 53(B: 107036-107754) & This study \\
\hline & Akan & Akan & 18(A: 91324-91919) & This study \\
\hline & Mashu & Mashu & 26(A: 120822-121088), 75(B: 155536-155804) & This study \\
\hline & Saroma & Saroma & 33(A: 137816-138389) & This study \\
\hline & Shikotsu & Shikotsu & 55(B: 111333-111487), 67(B: 128728-128985) & This study \\
\hline & Toya & Toya & 62(B: 123362-123471) & This study \\
\hline \multirow[t]{17}{*}{ Unknown } & \multirow[t]{2}{*}{ Basho } & \multirow[t]{2}{*}{ Basho } & 4(A: 57083-58173), 46(B: 96817-98291), 49(B: 100171-100705) & \multirow[t]{2}{*}{ Turcotte et al. (2001) } \\
\hline & & & 60(B: 120882-121251) & \\
\hline & Explorer & Explorer & 28(A: 123621-123805) & Bureau et al. (1996) \\
\hline & Wanderer & Wanderer & 8(A: 69603-69824) & Bureau et al. (1996) \\
\hline & Type Unique & Type Unique & 32(A: 136026-136128), 36(B: 75964-76185) & Tarchini et al. (2000) \\
\hline & Moiwa & Moiwa & 73(B: 154334-154487) & This study \\
\hline & Rishiri & Rishiri & 71(B: 139698-139937) & This study \\
\hline & Shari & Shari & 51(B: 103834-104257) & This study \\
\hline & Taisetsu & Taisetsu & 31(A: 135339-135595) & This study \\
\hline & Teine & Teine & 6(A: $65425-65665)$ & This study \\
\hline & Tengu & Tengu & 15(A: 84494-84563) & This study \\
\hline & Youtei & Youtei & 72(B: 153655-153790) & This study \\
\hline & RTBV-like & RTBV-like & 23(A: 112058-119385) & Nagano et al. (2000) \\
\hline & \multirow[t]{4}{*}{ Microsatellite } & MRG6379 & 11(A: 79154-79181) & AY024054 \\
\hline & & MRG0415 & 13(A: 81499-81522) & AYO18090 \\
\hline & & $(\mathrm{AT}) \mathrm{n}$ & 22(A: 111644-111987) & This study \\
\hline & & $(\mathrm{AT}$ or $\mathrm{AC}) \times 124$ & 24(A: 119462-119713) & This study \\
\hline
\end{tabular}

${ }^{a}:$ RS (repetitive sequence) no. is indicated below each red box in Fig. 1. Numbers in parentheses show the nucleotide position in Accession no. registered in AP000559(A) or AP002542(B). 
detected using the ECL gene detection system (Amersham).

\section{Accession numbers of TEs identified in this study} Each consensus sequence of the TEs identified in this study was surveyed by use of the rice genome database. Use of these consensus sequences readily identified the counterparts from the rice genome database. Thus, we registered these representatives to DDBJ, and the nucleotide sequences of the TEs and their accession numbers appear in Nucleotide Sequence Databases as follows: TabitoI: AB077830; TabitoII: AB077831; TabitoIII: AB078024; TabitoIV: AB078025; TabitoV: AB077832; TabitoVI: AB077833; KiseruI: AB077834; KiseruII: AB077835; KiseruIII: AB077836; KiseruIV: AB077837; Akan: AB077838; Mashu: AB077839; Saroma: AB077840; Shikotsu: AB077841; Toya: AB077842; Moiwa: AB077843; Rishiri: AB077844; Shari: AB077845; Taisetsu: AB077846; Teine: AB077847; Tengu: AB077848; Youtei: AB077849.

\section{RESULTS}

Search for RSs in the $200 \mathrm{~kb}$ around $\mathrm{wx}$ of the rice genome database The rice genome database is now available for $195 \mathrm{~kb}$ of the 260 -kb region surrounding the rice $w x$ locus examined here (as of November 2001). In this $195-\mathrm{kb}$ region, the rice genome project has identified 41 putative genes, including five unknown and 24 hypothetical genes (Fig. 1). The average sizes of the genes and spacers in this region are 2.02 and $2.87 \mathrm{~kb}$, respectively. We divided the $200-\mathrm{kb}$ region into 390 segments (each $500 \mathrm{bp}$ in length), and subjected these segments as blast search queries against the rice genome sequences registered in the DNA database. Sequences at different locations of the rice genome that hit the query (score over 80) were counted, and the blast-hit number was regarded as the reiteration frequency of each segment, as summarized in Fig. 1.

To examine whether the repetition of the segments used as queries reflects the actual copy number in the genome, we carried out Southern blot analysis using some representative segments as probes (Fig. 2). The segments determined by blast search to have single or low copy number in the genome showed a single or a few hybridized bands in Southern blotting (Fig. 2b, c, f). In the blotting pattern of a segment with 10 repetitions, about 20 bands were observed in the blot (Fig. 2d), and more highly repeated segments produced more bands or smeared patterns (Fig. 2a, e). These blotting results indicated that the repetitions recorded by blast analysis are mostly underscores, but are roughly correlated with the actual copy number. Of a total of 390 segments, 259 did not have similarity with other rice genomic regions. When sites that were scored as having less than 10 repetitions were classified as non-RSs, about $77 \%$ of total sites were included in this category. Segments with more than 50 reiterations were found in only 49 segments. Therefore, our previous finding by Southernblot analysis that $70 \%$ of the $200-\mathrm{kb}$ around the $w x$ locus consisted of repetitive regions (Nagano et al., 1999) was an apparent overestimation that was caused by abundant

Table 2. Categorization of TE subfamilies into Tourist, Tnr1/Stowaway and Mu-like families according to their TIRs and TSDs.

\begin{tabular}{|c|c|c|c|c|c|c|}
\hline Family & Subfamily & $\begin{array}{l}\text { Consensus sequence } \\
\text { of }^{\text {TIR }}{ }^{\mathbf{a}}\end{array}$ & $\begin{array}{l}\text { Maximum length } \\
\text { of TIR (bp) }\end{array}$ & $\begin{array}{l}\text { Length of } \\
\text { TSD (bp) }\end{array}$ & Reference & \\
\hline Tourist & $\begin{array}{l}\text { TouristI } \\
\text { Castaway } \\
\text { Ditto/TypeF } \\
\text { Gaijin } \\
\text { TypeC } \\
\text { TypeE } \\
\text { TabitoI } \\
\text { TabitoII } \\
\text { TabitoIII } \\
\text { TabitoIV } \\
\text { TabitoV } \\
\text { TabitoVI } \\
\text { Common }\end{array}$ & $\begin{array}{l}\text { GGGCCAGTTTAGTT } \\
\text { GGSCCCRTTTGA } \\
\text { GAGCARGTWYATAG } \\
\text { GGCTGTGTTAG } \\
\text { GGSTGTGTTTAG } \\
\text { GSSYKWGTTTAGTTCC } \\
\text { GGRYYGGTTRGTTTGWGRYCTAAATWRGM... } \\
\text { SGSYGTGTTTAGTTC } \\
\text { RGCCTTGTTCGKTT } \\
\text { GGGGSTGTTTRGWTKCCAGGGCTAAAATTT... } \\
\text { GGCTSTGTT } \\
\text { GGCTGTGTTTAG } \\
\text { GGSYSTGTTTRGTT }\end{array}$ & $\begin{array}{r}14 \\
12 \\
15 \\
12 \\
12 \\
16 \\
44 \\
15 \\
14 \\
160 \\
9 \\
12\end{array}$ & $\begin{array}{l}3 \\
3 \\
3 \\
3 \\
3 \\
3 \\
3 \\
3 \\
3 \\
3 \\
3 \\
3\end{array}$ & $\begin{array}{l}\text { Turcotte et al. } \\
\text { Bureau et al. } \\
\text { Bureau et al. } \\
\text { Bureau et al. } \\
\text { Tarchini et al. } \\
\text { Tarchini et al. } \\
\text { This study } \\
\text { This study } \\
\text { This study } \\
\text { This study } \\
\text { This study } \\
\text { This study }\end{array}$ & $\begin{array}{l}(2001) \\
(1996) \\
(1996) \\
(1996) \\
(2000) \\
(2000)\end{array}$ \\
\hline Tnrl/Stowaway & $\begin{array}{l}\text { Tnrl } \\
\text { Stowaway-Os1 } \\
\text { Stowaway-Os4 } \\
\text { TypeA } \\
\text { TypeB } \\
\text { KiseruI } \\
\text { KiseruII } \\
\text { KiserullI } \\
\text { KiserulV } \\
\text { Common } \\
\end{array}$ & $\begin{array}{l}\text { CTCCCTCCGYTTCTRAATATTCRCCGTTRT... } \\
\text { CTTCCTCCGTTCACAATTAAGTCATTCT... } \\
\text { CTCCCTCCGTCACATTTTAAGTGCAACTAT... } \\
\text { CTCCCTCCRTTTCATATTATAARYGTTTG... } \\
\text { CTACCTCCRTWTTTTAATAKATGACGCCGT... } \\
\text { CTCCCTCCRTACTCRTAAAGRAATCGTT... } \\
\text { CTCCCTCCGTCCMAAAATATAARCATTTT... } \\
\text { CTYCCTCYATCCYATAATATAAGGCGY } \\
\text { CTCCCTCCGTCCCAYAATATAAGGGATTTT... } \\
\text { CTCCCTCCRTYYYATAATATAAR }\end{array}$ & $\begin{array}{l}75 \\
70 \\
36 \\
37 \\
70 \\
36 \\
31 \\
27 \\
78\end{array}$ & $\begin{array}{l}2 \\
2 \\
2 \\
2 \\
2 \\
2 \\
2 \\
2 \\
2\end{array}$ & $\begin{array}{l}\text { Umeda et al. } \\
\text { Bureau et al. } \\
\text { Bureau et al. } \\
\text { Tarchini et al. } \\
\text { Tarchini et al. } \\
\text { This study } \\
\text { This study } \\
\text { This study } \\
\text { This study }\end{array}$ & $\begin{array}{l}(1991) \\
(1994 a) \\
(1994 a) \\
(2000) \\
(2000)\end{array}$ \\
\hline$M u$-like & $\begin{array}{l}\text { RMu-A23 } \\
\text { Mermite } \\
\text { Onagal } \\
\text { OnagalI } \\
\text { Common }\end{array}$ & $\begin{array}{l}\text { GAGAAAATTGTGATTTTGCTATCGCAAAAG... } \\
\text { GGAATAAGTTCACTTCGTACCTCARWGT.. } \\
\text { GGAAWAAGTWYAYKRAGGTCCCTTRACTT.. } \\
\text { GAGTAAAGTCCATCACCGGTCCCTAAACTT... } \\
\text { GRRAWAAGTTYAYYTCNGGTCCCTCAACTT }\end{array}$ & $\begin{array}{l}193 \\
177 \\
297 \\
383\end{array}$ & $\begin{array}{l}9 \\
9 \\
9 \\
9\end{array}$ & $\begin{array}{l}\text { AB023047 } \\
\text { Tarchini et al. } \\
\text { This study } \\
\text { This study }\end{array}$ & $(2000)$ \\
\hline
\end{tabular}

a: a consensus TIR motif of each TE subfamily was obtained by comparisons of at least 5 elements. Letters in black shadows show the consensus sequences of the TE families, letters in gray shadows contain consensus nucleotides. 
small RSs (mostly <500 bp) distributed in this region.

Characterization of the RSs To identify the repeated sequences in the 200-kb region, we performed blast analysis on 88 segments from this region that were reiterated more than 10 times in the rice genome (Fig. 1). The results obtained are summarized in Table 1 and Fig. 1. In the 88 segments, $41 \mathrm{RSs}$ were identified as previously described TEs, including class I and class II TEs and TEs not included in these classes. The class I elements in the region comprises only pSINE sequences found at three sites (Mochizuki et al., 1992; Mochizuki et al., 1993; Hirano et al., 1994), and no LTR elements were identified. The blast analysis identified 26 RSs homologous to known class II elements, and these RSs fell into 12 distinct subfamilies: 10 subfamilies were classified as known MITEs (Tourist and Tnr1/Stowaway family), which are short sequences $(<500 \mathrm{bp})$ with conserved TIRs and 2- or 3-bp target site duplications (TSDs) (Bureau and Wessler, 1992; Bureau and Wessler, 1994a; Bureau and Wessler, 1994b; Bureau et al., 1996; Tarchini et al., 2000), the rest were found to be similar to CACTA-like elements (Tarchini et al., 2000) or snapback elements (such as Mermite) (Tarchini et al., 2000). Eight of the RSs fell into neither of these TE classes, and contained TIRs and/or TSDs that have not been identified. These eight RSs were divided into four types of TEs with strong similarity (> 80\%) to Explorer (Bureau et al., 1996), Wanderer (Bureau et al., 1996), Type Unique (Tarchini et al., 2000) or Basho (Le et al., 2000; Turcotte et al., 2001), respectively. The rice Basho element, which carries minisatellite-like sequences, was found at four sites (Inukai and Sano, 2002). Basho is composed of repeats of a 78-bp unit sequence, with unit number varying from one

A

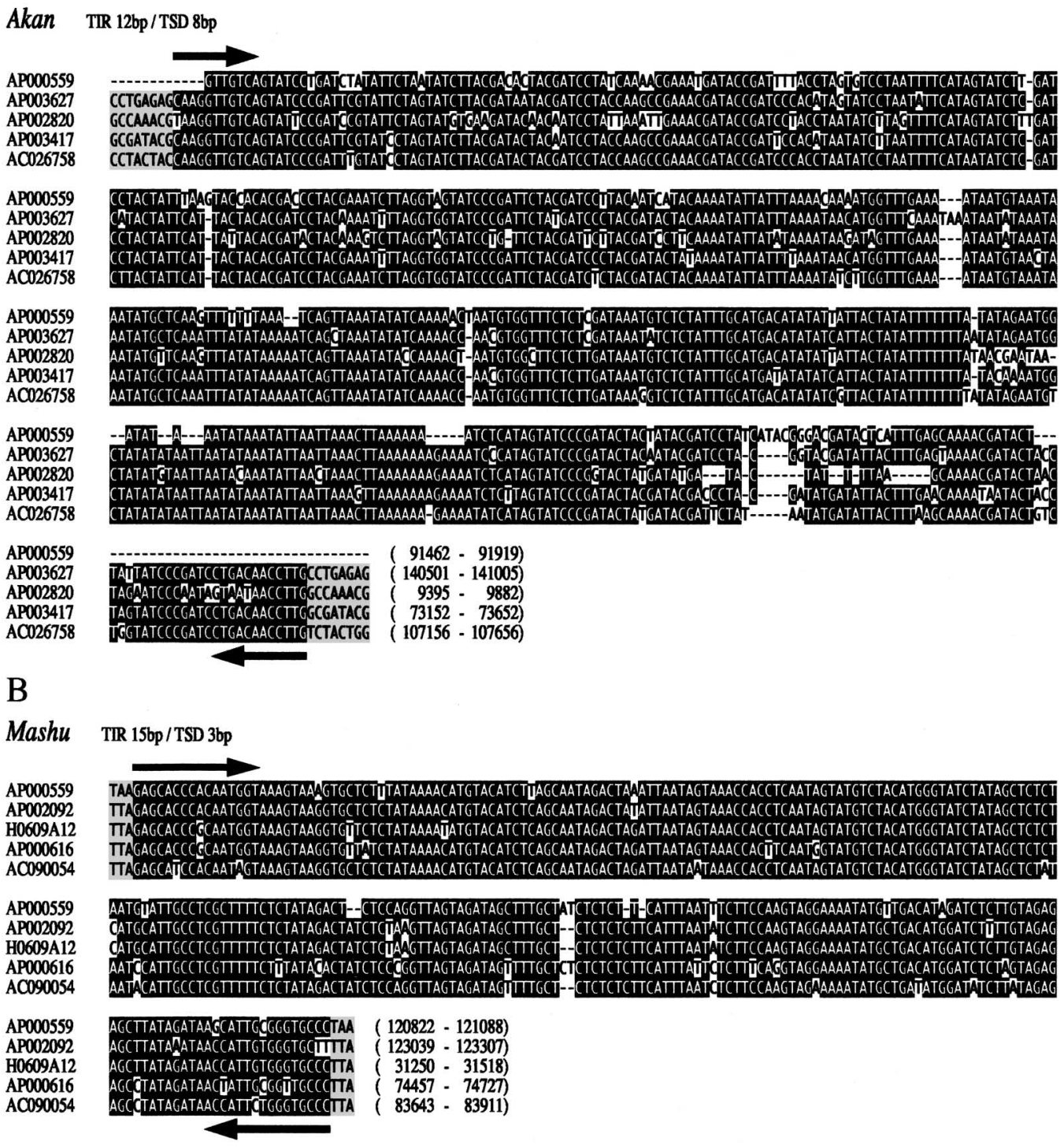


C

\begin{tabular}{|c|c|}
\hline Iroma & TIR 284bp / TSD 3bp \\
\hline 000559 & ACATTTAGAGTAAATTCATAAAACTACAGATACTIGCATGATCTATCACAAAACTA \\
\hline AP003292 & 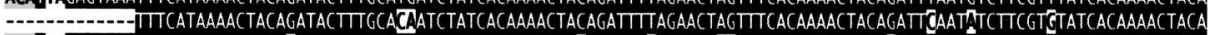 \\
\hline AC079022 & 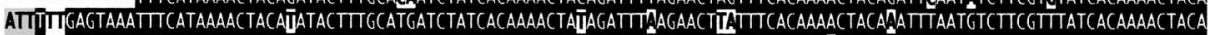 \\
\hline AC087544 & 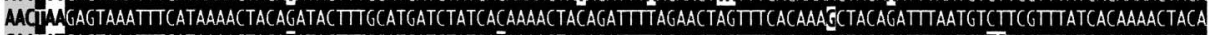 \\
\hline AC074283 & 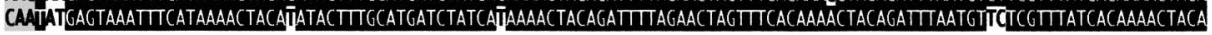 \\
\hline 00055 & \\
\hline AP003292 & 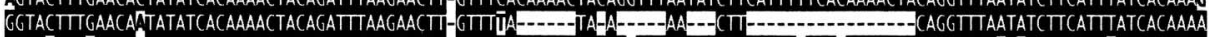 \\
\hline 79022 & GATTAAGAACTI-GTTCACAAAACTACAGAMTAATATCTCATTATCADAAAACTACAGGTTAGTGTCTTC \\
\hline & ACTACAGGTTAATATCTTCATTIT CACAAAACTACAGGTTAATATÜTTCATTATCACAAAA \\
\hline 74283 & tACTTGAaCACTATATCAĨAAAACTAUAGATTIAAGAACTTAGTT CACAAAACTACG \\
\hline
\end{tabular}

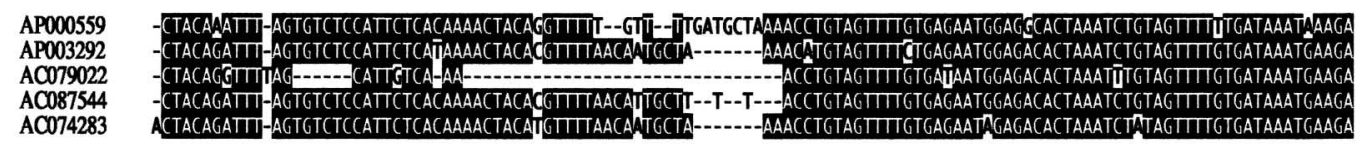

AP000559

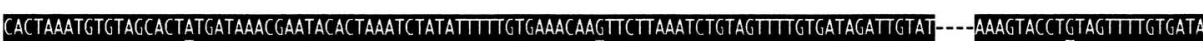
CaCtAAATGTGTAGCACTGTGATAAACGAATACACTAAATCTATATTाT GTGAAACAAITTCTTAAATCTGTAGTITGTGATAGATTGTAC---AAAGTACCTCTAGTITGTGATA

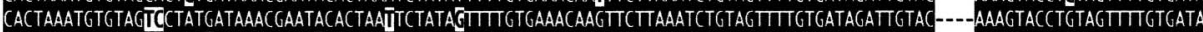

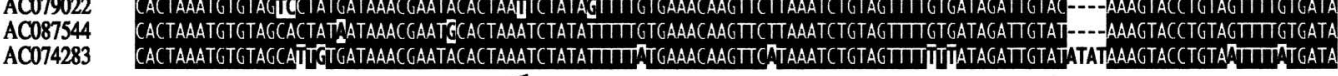
AC074283

AP000559 AP003292 AC079022 AC087544 AC074283

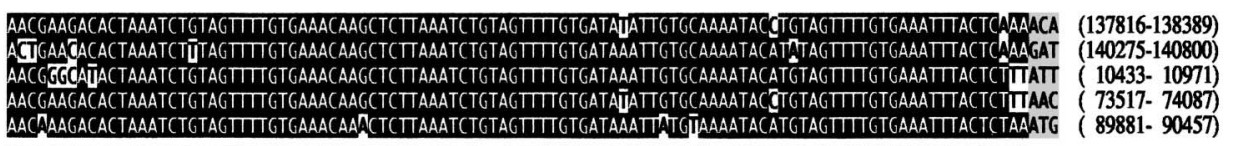

D

Shikotsu TIR 11bp/TSD 8bp

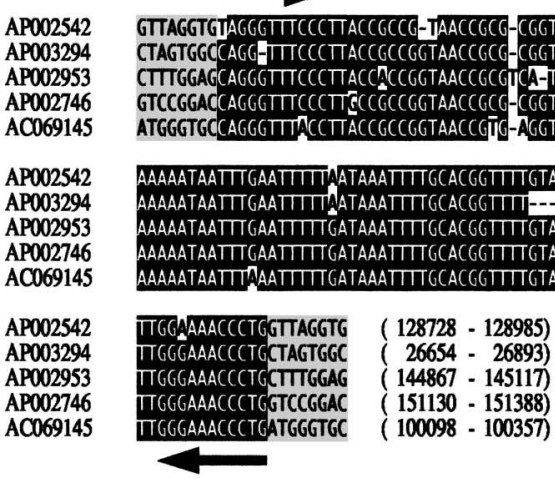

E

Toya TIR 10bp / TSD 8bp

AP002542 AP003144

AC084320

AC084218

AC091734

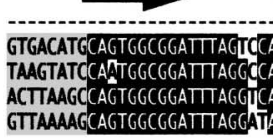

AGTCCATTTCTGTGGGGTCGGCTGACCCCACAGCTIITGAAAAAC

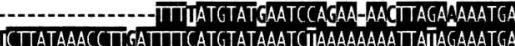

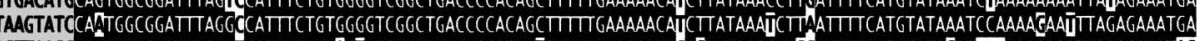

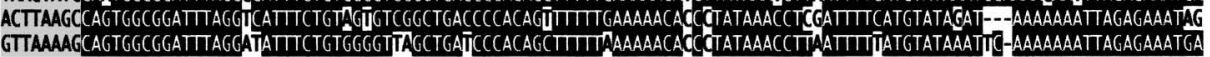

AP002542

AP003144

AC084320

AC084218

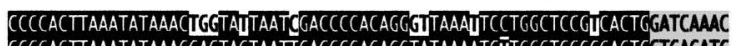

$(123362-123468)$

CCCACTTAAATATAAACCACTAGTAATTGACCCCACAGGTATAAAATCĪTGGCTCCGCCACTGGTGACATG

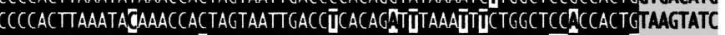

CCCCACTTAAATATAAACCAITTAGTAATTGACCTCACAGGTATAAAATCCTGGCTATGCCACTTACTTGAGC

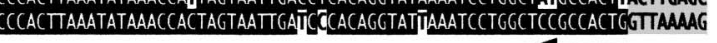

$636-827)$

3486 - 3677

79098 - 79280

23118 - 23308)

Fig. 3. Five new families of class II elements identified in the $200-\mathrm{kb}$ region around $w x$.

Five new members of each family were identified in the rice genome accessions denoted on the left side, and their positions are noted at the end of the alignment. The black shadows in the alignments show consensus sequences of the family members. The arrows indicate TIRs and the gray shadows represent TSDs. 
to six among the elements. Four microsatellite sequences, two of which were deposited in the database, were found in this $200-\mathrm{kb}$ region.

The remaining $34 \mathrm{RSs}$ were unidentified elements, each of which has highly homologous copies $(>80 \%)$ located in other genomic segments. A computer-aided search indicated that 26 RSs have TIR or TIR-like sequences, but seven RSs have no detectable characteristics of known TEs or characteristics of RSs such as microsatellites. Curiously, some continuous segments (RS no. 23) located about $50 \mathrm{~kb}$ upstream of $w x$ showed similarity to the rice tungro bacilliform virus (RTBV), which is a pararetrovirus. Recent reports suggest that plant pararetrovirus DNA might integrate rather frequently into host chromosomes (Jakowitsch et al., 1999; Harper et al. 1999; Ndowora et al., 1999).

Classification of TE-like sequences Of a total of 75 RSs found in this study, we accounted for $37 \mathrm{RSs}$ as known TEs, while 26 newly discovered RSs are possible class II elements, because they possess TIRs. The entire sequences of these $26 \mathrm{RSs}$ have little similarity to the sequences of previously reported TEs. However, classification of TEs has usually been based on TIR and target site duplication (TSD) sequences. Hence, we compared the TIR structures with those of known elements. Turcotte et al. (2001) reported that the rice TEs were categorized into three major groups: Tnr1/Stowaway, Tourist and $\mathrm{Mu}$-like families. Using their classification system based on the identities of TIR and TSD, 19 RSs found in this study were categorized into the three TE families, and their subfamilies were sorted out by the entire similarity (> 80\%) in addition to TIR and TSD as follows:

Tourist family: Tourist was originally discovered in the maize $w x-B 2$ allele (Bureau and Wessler, 1992), and Bureau and Wessler (1994) also identified Tourist-like elements in the rice genome. These elements have a consensus TIR sequence, GGGCCAGTTTAGTT, with a three-nucleotide (TTA) TSD (Table 2). Other elements in this category, Castaway (Bureau et al. 1996), Ditto/ MITE-Type F (Bureau et al., 1996; Tarchini et al., 2000), Gaijin (Bureau et al., 1996), MITE-Type C and E (Tarchini et al., 2000) possess similar terminal sequences, as shown in Table 2. Furthermore, we identified $10 \mathrm{RSs}$ which we classified into the Tabito (Tourist in Japanese) I-VI subfamilies, which also harbor Tourist-like terminal sequences, and have flanking 3-bp TSDs (Table 2). A total of $21 \mathrm{RSs}$ in the $200-\mathrm{kb}$ region examined appear to be classifiable into the Tourist family. The common TIR motif of the Tourist family was identified as GGSYSTGTTTRGTT.

Tnr1/Stowaway family: Tnr1 was first discovered in an intron of the rice $w x$ gene by Umeda et al. (1991), and subsequently Bureau and Wessler (1994) independently identified Stowaway in a wide range of plant species. These two types of elements are structurally similar, and here we refer to them as Tnr1/Stowaway. Among the unclassified RSs in this study, the ends of the Kiseru (Stowaway in Japanese) I-IV sequences shared a common TIR motif with the ends of the Tnr1/Stowaway elements, although the other structures and the sizes of the TIRs varied among the elements (Table 2). In addition, the MITEType A and B elements described by Tarchini et al. (2000) also appear to have a TIR motif analogous to that of Tnr1/ Stowaway (Table 2). Thus, a total of 17 elements possibly belonging to the Tnr1/Stowaway family were found in the 200-kb region. The common TIR motif of the Tnr1/ Stowaway family is CTCCCTCCRTYYYATAATATAAR, and TA is a typical preferred target site for these elements (Table 2).

Mu-like family: According to Yu et al. (2000), Mu-like elements contain long TIRs (>100 bp) with a 10-bp consensus motif (GGGGAAAAAT) at the termini and 9-bp TSDs. Mermite (Tarchini et al., 2000), which possesses GA-rich ends and TIRs longer than $160 \mathrm{bp}$ and generates a 9-bp TSD, shows Mu-like characteristics (Table 2). Mermite forms a snapback structure. The six $\mathrm{Mu}-$ like RSs found in the 200-kb region share these common features: long TIRs with GA-rich ends, 9-bp TSDs and snapback structure (Table 2). Their TIR sequences are also quite similar to those of Mermite, and were analyzed to determine a consensus motif (Table 2). The elements were divided into two subfamilies, named Onaga ("long tail" in Japanese) I and II. We judged that these six RSs, like Mermite, belong to a Mu-like family.

Identification of new TEs Fourteen RSs did not match any of the known TEs. These unidentified sequences included seven possible TEs, whose ends contained TIRs. The seven RSs were classified into five elements: Akan, Mashu, Saroma, Shikotsu and Toya. Mashu and Shikotsu appeared at two sites in this 200-kb region. Each of these five elements is quite conserved in the rice genome, as shown in Fig. 3A-E. The individual elements contain distinct TIR sequences. Saroma has remarkably long TIRs (200-284 bp) that form snapback structures (Fig. 3C). The 3-bp TSD of this element is different from that of Mu-like elements, which contain 9-bp TSDs. We could not find complete TIRs for Akan and Toya in the 200-kb region, but we discovered their TIRs in other locations (Fig. 3A and E). These newly identified elements are reiterated at low frequency as shown by the blast search, and the entire structures of the element are relatively less divergent within a given family compared with the structure of the Tnr1/Stowaway, Tourist and Mu-like families (data not shown). This suggests that their invasion into the rice genome occurred relatively recently.

The sequences of seven RSs, namely Moiwa, Rishiri, Shari, Taisetsu, Teine, Tengu and Youtei, could not be 
Table 3. Conservation of sequences that were identified as possible TE elements in the rice genome but which do not have typical TE characteristics.

\begin{tabular}{|c|c|c|c|}
\hline $\begin{array}{l}\text { Name of } \\
\text { unknown RS }\end{array}$ & Sequence found in the region around $w x$ & $\begin{array}{l}\text { Similar sequences found } \\
\text { in the other regions }\end{array}$ & $\underset{\left(\mathscr{F}^{\prime}\right)}{\text { Identity }}$ \\
\hline Moiwa & $\begin{array}{l}\text { TAAAAGGTGGCGGCGGTCCTAATCCATTGGACTAGTCTTTTGGGCTGTGTAGGCTCAGGA } \\
\text { CCTAAAGTTGTGGCTCTGGTTAGGCTTGTGGTGAAGCAGGCCATGTATCTGGTGAC } \\
\text { CCATAGTTGGTGGACCAGGTTGGCACTCTAACA }\end{array}$ & $\begin{array}{l}\text { AC079890 } \\
\text { AC091732 } \\
\text { AJ307662 } \\
\text { AP001550 } \\
\text { AP002485 }\end{array} \quad\left\{\begin{array}{ll}32920 & -33074) \\
81826 & -81980 \\
87368 & -27151 \\
98511 & -98661\end{array}\right)$ & $\begin{array}{l}89.0 \\
87.7 \\
86.0 \\
86.0 \\
81.8\end{array}$ \\
\hline Rishiri & 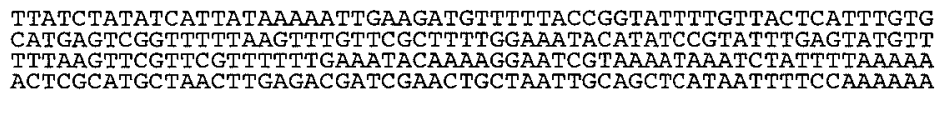 & $\begin{array}{ll}\text { AP000069 } & (76848-77086) \\
\text { AF172282 } & (300200-300436) \\
\text { AC079887 } & (69157-69399) \\
\text { AP003199 } & (108439-108676) \\
\text { AP003022 } & (99665-99906)\end{array}$ & $\begin{array}{l}80.4 \\
80.0 \\
79.2 \\
77.9 \\
75.8\end{array}$ \\
\hline Shari & 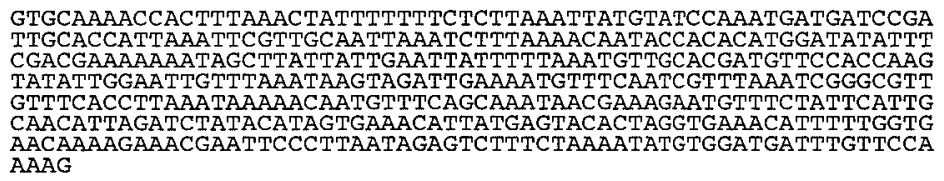 & $\begin{array}{l}\text { AC034258 } \\
\text { AP0675A05 } \\
\text { AP002599 } \\
\text { AL } 1100311035-110462) \\
\text { AC079887 }\end{array} \quad \begin{array}{l}17588-18015) \\
103245-103631 \\
167297-167724)\end{array}$ & $\begin{array}{l}90.3 \\
89.2 \\
88.9 \\
79.2 \\
78.1\end{array}$ \\
\hline Taisetsu & $\begin{array}{l}\text { AGGTAGTGTTTGGTTGCAAGGATGGGATAGAATGGGATGGGATGAACCCACTTTTAGGGG } \\
\text { TGTTTGGTTGAGAGGCGATGGGATGGTTGGTCCCTGGAGAGAAATATTCCTCTCAGAT } \\
\text { CCGGGACGAAGTGGTCCGCCAAAATCAGCCAGACCAATCCATCCCACTTCGACCGAGCGA } \\
\text { ACGGCGTCAGCT }\end{array}$ & $\begin{array}{ll}\text { AC068924 } & \left(\begin{array}{l}144842-145033) \\
\text { AP003222 } \\
\text { AP003282 }\end{array}\right. \\
\text { AP000391 } & (655791-6062) \\
\text { AP003487 } & (26620-26810) \\
29924 & -30102)\end{array}$ & $\begin{array}{l}91.1 \\
90.6 \\
88.0 \\
84.4 \\
81.3\end{array}$ \\
\hline Teine & $\begin{array}{l}\text { GCGAAGTAAGCGTAGCTCATCTGGTTAGGTTCCTTGTGGAGGAACTAGTCCACCTACATT } \\
\text { CAAATCCTAAATTGTTCGCATTTATGGCTAATTATTCTTTTAATGGTAGACGACGTACC } \\
\text { CGTCGACAGCGAGACGTTGGTGACTTCGTCAATCTCAAGATTTGTTGGTCCAATCTTCCG } \\
\text { AAGAGACTCATATGGATAGGGGATA }\end{array}$ & $\begin{array}{lll}\text { AC026815 } & (82575 & -82791 \\
\text { AP003046 } & (83906 & -84122 \\
\text { AP002485 } & 91040 & -91256) \\
\text { AP003210 } & (30114 & -30345) \\
\text { AL } 442110 & (85995 & 86209)\end{array}$ & $\begin{array}{l}79.5 \\
76.1 \\
75.6 \\
73.7 \\
72.2\end{array}$ \\
\hline Tengu & $\begin{array}{l}\text { TTTGAACCAGAACTAAAAATAATCTTTAGTCCCGGTTCCTATTCGAACCAGGACTATTGT } \\
\text { GGATTTTGGG }\end{array}$ & 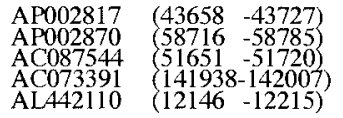 & $\begin{array}{l}88.6 \\
87.1 \\
87.1 \\
87.1 \\
77.1\end{array}$ \\
\hline Youtei & $\begin{array}{l}\text { ACTAGCAATTATTATCTAGAGTATTTTAAATATCATGCAAACATGATATATCAATTACAA } \\
\text { TTTTGTTGTATTTTTAGAACTCAATATGCAACCAATGTCAAATCATTATCTCCACTTCAT } \\
\text { TTTCACACTATTAAA }\end{array}$ & $\begin{array}{ll}\text { AP003296 } & (137134-137270) \\
\text { AP002953 } & (132484-132619) \\
\text { AC } 027660 & (44135-44271) \\
\text { AC073393 } & (106378-106511) \\
\text { AP003213 } & (122239-122374)\end{array}$ & $\begin{array}{l}89.0 \\
87.5 \\
87.5 \\
87.5 \\
86.8\end{array}$ \\
\hline
\end{tabular}

a: Accession no, and nucleotide positions of each similar sequence.
b: The identity between a repeated sequence found in the region around $w x$ and a similar sequence in a different region was calculated.

easily classified as typical TE, since we failed to detect in them any characteristics of TEs. In contrast to the case of the RTBV-like sequence described above, no particular homology to any known sequence have been found in these RSs so far. It was also difficult to find the RESites (Le et al., 2000) for the empty donor sites of these elements in the rice genome database. In Table 3, we summarize the locations and homologies of these seven RSs and the corresponding sequences at five different locations. All of these sequences showed more than $70 \%$ identity with the similar sequences at the other locations. Like Basho (Le et al., 2000), Crackle (Turcotte et al., 2001), Explorer (Bureau et al., 1996), and Type Unique element (Tarchini et al., 2000), whose transposition mechanisms are unclear, the RSs found in this study may be novel types of TEs. It is notable that such novel RSs with yet unknown structures constituted $10 \%$ of the total RSs. This fact leads us to assume that numerous unknown RSs remain to be found.

\section{DISCUSSION}

This study examined the content and structures of the $\mathrm{RSs}$ present in the $200-\mathrm{kb}$ region around the $w x$ locus in the rice genome. We identified $75 \mathrm{RSs}$ in this region and classified them into 46 subfamilies, of which 23 were newly identified types of TEs or possible TEs. The average interval between $\mathrm{RSs}$ in the $200-\mathrm{kb}$ region was estimated to be $2.7 \mathrm{~kb}$, implying that there is on average one $\mathrm{RS}$ per spacer. In fact, $44 \mathrm{RSs}$ were distributed in spacer regions, and $19 \mathrm{RSs}$ resided in introns. Most of the RSs were short ( $<500 \mathrm{bp})$, and no long RSs ( $>5000 \mathrm{bp})$ such as LTR elements were observed in this region. Our results showed that these short elements possess various structural features, implying the presence of diverse and abundant class II elements in the rice genome. The properties of RSs detected in this local survey around $w x$ are in accord with the findings of the overall genome survey of rice (Turcotte et al., 2001). Similarly, the compact genome of Arabidopsis tends to contain relatively few class I elements and an abundance of class II elements. In addition to these findings, we found a much larger number of novel TEs and unknown RSs than expected based on the overall genome surveys of rice (Turcotte et al., 2001) and Arabidopsis (Le et al., 2000): (proportion of unclassified elements: in the rice $w x$ region: 17\%; the overall rice genome: $3 \%$; the overall Arabidopsis genome; 0.3\%), suggesting that a large number of unknown elements remain to be mined.

We do not yet know whether all TEs in the same family 
share a common transposase, or the different subfamilies of TEs utilize individual transposases, which would complicate the classification of TEs. Each subfamily of class II elements was found to contain unique TIRs, and even in the same TE family, the consensus TIR of each subfamily within the family was slightly different (shown in Fig. 3). These facts could be simply explained by the possibility of divergent transposases. Most of the elements detected thus far should lack the ability to transpose due to loss of the transposase. The divergent TIR sequences might reflect the evolutionary history of each TE family. Indeed, the TEs found in this study are differentially distributed in various Oryza species (Nagano, Kishima and Sano, unpublished data). Prior to the rice speciation, various class II elements must have invaded or been generated at different times and then evolved.

Deshpande and Ranjeker (1980) estimated by means of a Cot assay that the RS segments account for $50 \%$ of the content of rice genome. Recently, Tarchini et al. (2000) estimated the contribution of TEs to $340 \mathrm{~kb}$ of the rice Adh1-Adh2 region in chromosome 11 as $28.5 \%$. Turcotte et al. (2001) also surveyed $910 \mathrm{~kb}$ of the rice genomic DNA and found that TEs constituted $19.9 \%$ of the examined regions. In the present study, only $15 \%$ of the $200-\mathrm{kb} w x$ region showed repetitive characteristics. Although the proportion of RSs in the region around $w x$ might thus be lower than that in the other genomic regions noted above. TE- or TE-like sequences occur more frequently in the $w x$ region than in the other reported regions: the average densities of TEs in the $w x$ region, Adh1-Adh2 region and $910 \mathrm{~kb}$ of rice genomic DNA can be calculated as one in every $2.95 \mathrm{~kb}, 3.51 \mathrm{~kb}$ and $4.5 \mathrm{~kb}$, respectively. There are 41 annotated genes, including five unknown and 24 hypothetical genes in the $200-\mathrm{kb} w x$ region around the rice $w x$ gene. Hence, the average sizes of the genes and spacers in this region are 2.02 and 2.87 $\mathrm{kb}$, respectively. Thus, one TE or TE-like element would be expected to be located in every spacer. On the other hand, the absence of LTR elements in this region probably accounts for the lower percentage of total length of RSs and the higher density of RSs. This particular set of properties might influence the recombination frequency. Inukai et al. (2000) analyzed the recombination frequency within the $w x$ locus by means of pollen analysis of the $w x$ region and estimated it as $27.3 \mathrm{cM} / \mathrm{kb}$, which is about 10 times higher than $250-300 \mathrm{~kb} / \mathrm{cM}$ for the rice genome on average. Fu et al. (2001) found that an unusually high recombination frequency of the bronze locus of maize is associated with a gene-rich region. Duret et al. (2000) observed that regions with a high recombination rate in Caenorhabditis elegans preferentially contain class II elements rather than class I elements. The region surrounding the $w x$ locus appears to possess both of these properties, high gene density and a higher number of class II elements, found to be associated with a high recombination frequency in other systems. Therefore, it will be interesting to analyze the recombination frequency in the region examined in this study.

We are especially grateful to Prof. T. Mikami (Hokkaido Univ.) for providing the laboratory facilities. We also thank Ms. A. Takahashi for technical assistance. This work was supported by grants from the Ministry of Education, Science and Culture, Japan, and the Rice Genome Research Program (RGP).

\section{REFERENCES}

Akagi, H., Yokozeki ,Y., Inagaki, A. and Fujimura, T. (1996) Microsatellite DNA markers for rice chromosomes. Theor. Appl. Genet. 94, 61-67.

Arumuganathan, K. and Earle, E. D. (1991) Nuclear DNA content of some important plant species. Plant Mol. Biol. Rep. 9, 208-218.

Bennetzen, J. L. (2000) Transposable element contributions to plant gene and genome evolution. Plant Mol. Biol. 42, 251-269.

Britten. R. J. and Kohne, D. E. (1968) Repeated sequences in DNA. Hundreds of thousands of copies of DNA sequences have been incorporated into the genomes of higher organisms. Science 161, 529-540.

Bureau. T. E., Ronald, P. C. and Wessler, S. R. (1996) A computer-based systematic survey reveals the predominance of small inverted-repeat elements in wild-type rice genes. Proc. Natl. Acad. Sci. USA 93, 8524-8529.

Bureau, T. E. and Wessler, S. R. (1992) Tourist: a large family of small inverted repeat elements frequently associated with maize genes. Plant Cell 4, 1283-1294.

Bureau, T. E. and Wessler, S. R. (1994a) Stowaway: a new family of inverted repeat elements associated with the genes of both monocotyledonous and dicotyledonous plants. Plant Cell 6, 907-916.

Bureau, T. E. and Wessler, S. R. (1994b) Mobile inverted-repeat elements of the Tourist family are associated with the genes of many cereal grasses. Proc. Natl. Acad. Sci. USA 91, 1411-1145.

Charlesworth, D. and Charlesworth, B. (1995) Transposable elements in inbreeding and outbreeding populations. Genetics 140, 415-417.

Deshpande, V. G. and Ranjeker, P. K. (1980) DNA in three graminea species with low DNA content. Hoppe-Seyler's Z. Physiol. Chem. 361, 1223-1233.

Dubcovsky, J., Ramakrishna, W., SanMiguel, P. J., Busso, C. S., Yan, L., Shiloff, B. A. and Bennetzen, J. L. (2001) Comparative sequence analysis of colinear barley and rice bacterial artificial chromosomes. Plant Physiol. 125, 1342-1353.

Duret, L., Marais, G. and Biemont, C. (2000) Transposons but not retrotransposons are located preferentially in regions of high recombination rate in Caenorhabditis elegans. Genetics 156, 1661-1669.

Fu, H., Park, W., Yan, X., Zheng, Z., Shen, B. and Dooner, H. K. (2001) The highly recombinogenic $b z$ locus lies in an unusually gene-rich region of the maize genome. Proc. Natl. Acad. Sci. USA 98, 8903-8908.

Harper, G., Osuji, J. O., Heslop-Harrison, J. S. and Hull, R. (1999) Integration of banana streak badnavirus into the Musa genome: molecular and cytogenetic evidence. Virology 255, 207-213.

Hirano, H. Y., Mochizuki, K., Umeda, M., Ohtsubo, H., Ohtsubo, E. and Sano, Y. (1994) Retrotransposition of a plant SINE 
into the wx locus during evolution of rice. J. Mol. Evol. 38, 132-137.

Inukai, T., Sako, A., Hirano, H. Y. and Sano, Y. (2000) Analysis of intragenic recombination at $w x$ in rice: correlation between the molecular and genetic maps within the locus. Genome 43, 589-596.

Inukai, T and Sano, Y. (2002) Sequence rearrangement in the AT-rich minisatellite of the novel rice transposable element Basho. Genome in press.

Jakowitsch, J., Mette, M. F., van Der Winden, J., Matzke, M. A. and Matzke, A. J. (1999) Integrated pararetroviral sequences define a unique class of dispersed repetitive DNA in plants. Proc. Natl. Acad. Sci. USA 96, 13241-13246.

Jurka, J. (1998) Repeats in genomic DNA: mining and meaning. Curr. Opin. Struct. Biol. 8, 333-337.

Le, Q. H., Wright, S., Yu, Z. and Bureau, T. (2000) Transposon diversity in Arabidopsis thaliana Proc. Natl. Acad. Sci. USA 97, 7376-7381.

McDonald, J. F. (1999) Evolution and consequences of transposable elements. Curr. Opin. Genet. Dev. 3, 855-864.

Mochizuki, K., Ohtsubo, H., Hirano, H., Sano, Y. and Ohtsubo E (1993) Classification and relationships of rice strains with AA genome by identification of transposable elements at nine loci. Jpn. J. Genet. 68, 205-217.

Mochizuki, K., Umeda, M., Ohtsubo, H. and Ohtsubo, E. (1992) Characterization of a plant SINE, p-SINE1, in rice genomes. Jpn. J. Genet. 67, 155-166.

Nagano, H., Wu, L., Kawasaki, S., Kishima, Y. and Sano, Y. (1999) Genomic organization of the $260 \mathrm{~kb}$ surrounding the waxy locus in a Japonica rice. Genome 42, 1121-1126.

Nagano, H., Kawasaki, S., Kishima, Y. and Sano, Y. (2000) Structural differences in the vicinity of the waxy locus among the Oryza species with the AA-genome: identification of variable regions. Theor. Appl. Genet. 100, 376-383.

Ndowora, T., Dahal, G., LaFleur, D., Harper, G., Hull, R., Olsze- wski, N.E. and Lockhart, B. (1999) Evidence that badnavirus infection in Musa can originate from integrated pararetroviral sequences. Virology 255, 214-220.

SanMiguel, P., Tikhonov, A., Jin, Y. K., Motchoulskaia, N., Zakharov, D., Melake-Berhan, A., Springer, P.S., Edwards, K. J., Lee, M., Avramova, Z. and Bennetzen, J. L. (1996) Nested retrotransposons in the intergenic regions of the maize genome. Science 274, 765-768.

Tarchini, R., Biddle, P., Wineland, R., Tingey, S. and Rafalski, A. (2000) The complete sequence of $340 \mathrm{~kb}$ of DNA around the rice Adh1-adh2 region reveals interrupted colinearity with maize chromosome 4. Plant Cell 12, 381-391.

Temnykh, S., DeClerck, G., Lukashova, A., Lipovich, L., Cartinhour, S. and McCouch, S. (2001) Computational and experimental analysis of microsatellites in rice (Oryza sativa L.): frequency, length variation, transposon associations, and genetic marker potential. Genome Res. 11, 1441-1452.

Thomas, C. A. (1971) The genetic organization of chromosomes. Annu. Rev. Genet. 5, 237-256.

Turcotte, K., Srinivasan, S. and Bureau, T. (2001) Survey of transposable elements from rice genomic sequences. Plant J. 25, 169-179.

Umeda, M., Ohtsubo, H. and Ohtsubo, E. (1991) Diversification of the rice Waxy gene by insertion of mobile DNA elements into introns. Jpn. J. Genet. 66, 569-586.

Wessler, S. R., Bureau, T. E. and White, S. E. (1995) LTR-retrotransposons and MITEs: important players in the evolution of plant genomes. Curr. Opin. Genet. Dev. 5, 814-821.

Wu, K. S. and Tanksley, S. D. (1993) Abundance, polymorphism and genetic mapping of microsatellites in rice. Mol. Gen. Genet. 241, 225-235.

Yu, Z., Wright, S. I. and Bureau, T. E. (2000) Mutator-like elements in Arabidopsis thaliana. Structure, diversity and evolution. Genetics 156, 2019-2031. 